\title{
Nonoperative Management for Peri-Appendiceal Abscesses after Percutaneous Drainage Without Interval Appendectomy
}

\section{Chang Sung Park}

Yonsei University College of Medicine

In A Lee

Yonsei University College of Medicine

Yun Tae Jung

University of Ulsan College of Medicine

Jae Gil Lee ( $\nabla$ jakii@yuhs.ac )

Yonsei University College of Medicine

\section{Research Article}

Keywords: Peri-appendiceal abscess, non-operative management, appendicitis

Posted Date: December 10th, 2021

DOI: https://doi.org/10.21203/rs.3.rs-1150736/v1

License: (a) (i) This work is licensed under a Creative Commons Attribution 4.0 International License.

Read Full License 


\section{Abstract}

Background: Initial non-operative management (NOM) with percutaneous drainage for peri-appendiceal abscesses has been proven to be safe and effective. However, the appropriateness of interval appendectomy after NOM is still a matter of debate. The aim of this study was to investigate the feasibility of NOM without performing interval appendectomy.

Methods: A retrospective review of medical records was performed for patients who were admitted with peri-appendiceal abscesses between January 2009 and December 2019. After percutaneous drainage for the abscesses, whether to undergo interval appendectomy was decided by the patients. Their clinical courses were reviewed thoroughly through their medical records. Telephone contact with these patients was made when necessary.

Results: Twenty-seven patients were enrolled, with a mean age of 63.1 years ( \pm 11.9 years). The median follow-up period was 25.7 months. The most common co-morbidities were cardiovascular disorders (eight patients) and underlying malignancies (eight patients). The mean size of the abscesses was $5.4 \mathrm{x}$ $4.1 \otimes$. Three patients consequently received surgery for the recurrence of appendicitis or peri-appendiceal abscesses. One patient received a right hemicolectomy, and another two received open appendectomies. Four patients $(14.8 \%)$ died within the follow-up period due to underlying diseases.

Conclusion: Initial NOM without interval appendectomy was a safe option in selected patients with periappendiceal abscess.

\section{Background}

Acute appendicitis is the most common cause of intra-abdominal infections, and a considerable proportion of cases are complicated ${ }^{1}$. Appendectomy remains the gold-standard treatment for acute appendicitis in international guidelines ${ }^{2-4}$. However, patients with complicated appendicitis with extensive inflammation might need to receive surgical resections beyond appendectomy, such as ileocecal resection or right hemicolectomy. They also have a high risk of complications after surgical treatment. Initial non-operative management(NOM) in selected cases with peri-appendiceal abscesses has recently been reported to be safe and effective ${ }^{3}$, with fewer complications than emergency appendectomy in these cases $^{4,5}$. Therefore, performing initial NOM including antibiotic therapy and percutaneous drainage is accepted as a standard therapy for peri-appendiceal abscesses. Interval appendectomy was the main therapeutic option after initial NOM for peri-appendiceal abscesses, and preoperative colonoscopies were recommended to check for the possibility of malignancy ${ }^{6}$. The reported rates of recurrence vary from $5 \%$ to $40 \%$, but the respective studies enrolled small numbers of patients, and the follow-up periods were short $^{7}$. Interval appendectomy confers a risk of developing complications ${ }^{8}$. Furthermore, a low recurrence rate without interval appendectomy has been reported ${ }^{8}$. Therefore, the appropriateness of interval appendectomy following initial NOM for peri-appendiceal abscess is still a matter of debate. 
The aim of this study was to evaluate the recurrence rate after initial NOM without interval appendectomy for peri-appendiceal abscesses and to assess the necessity of interval appendectomy.

\section{Methods}

\section{Study population}

Hospital databases were searched to identify patients diagnosed with peri-appendiceal abscesses with procedure records for percutaneous drainage between January 2009 and December 2019.Theelectronic medical records of the 85 patients who were selected during the process were thoroughly reviewed. Among them, 27 patients were finally included for analysis, who received abscess drainage procedures for peri-appendiceal abscesses and planned to proceed with NOM. Patients who chose to receive delayed surgery after percutaneous abscess drainage or interval appendectomy without recurrence were excluded.

\section{Treatment flow for peri-appendiceal abscess}

Our surgical team followed the treatment guidelines published by the World Society of Emergency Surgery ${ }^{2}$. Surgical management is accepted as the gold-standard treatment for both simple acute appendicitis and perforated acute appendicitis. Appendectomy was performed as an initial treatment method in the following situations: 1) an abscess had formed at the tip or body of the appendix, with an

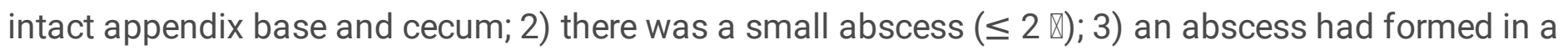
deep pelvic cavity or surrounded by adjacent bowel, which made the percutaneous approach difficult and risky. Patients with remaining abscesses and symptoms of appendicitis were managed by delayed appendectomy or resectional surgery.

For patients who underwent percutaneous drainage for peri-appendiceal abscesses, detailed counselling was carried out by a responsible surgeon to establish a further treatment plan. After pigtail insertion, the patients were checked by outpatient clinics. If the clinical presentation had disappeared and signs of recurrence were absent or the abscess was not found on the computed tomography (CT) scan, the next therapeutic step was discussed with the patient. Additionally, if the patient did not wish to undergo surgery and accepted the risks of recurrence, then the pigtail catheter was removed 4 to 6 weeks after insertion. Additionally, the surgical team told the patient to visit the clinic or emergency room if they had any symptoms or signs of possible acute appendicitis. Non-operative management was performed if the following criteria applied: 1) the patient did not want to undergo surgery; 2) the patient had risk factors for postoperative complications, such as severe underlying comorbidities; 3 ) the patient had other intraabdominal pathologies, such as metastatic cancer or carcinomatosis.

\section{Data collection}

Baseline characteristics, such as age, sex, and comorbidities, were collected through the electronical medical record. The initial complete blood counts, initial delta-neutrophil indices, C-reactive protein (CRP) 
levels, initial vital signs, clinical outcomes, and lengths of the follow-up periods were also collected. Telephone calls were made to the patients to obtain information beyond that in their hospital records.

\section{Statistical analysis}

The patients' baseline characteristics, initial statuses, and follow-up periods are expressed as medians (interquartile ranges) or means ( \pm standard deviations). Categorical variables are presented as frequency (\%). Statistical analysis was performed using SPSS ${ }^{\circledR}$ Statistics 23.0 (IBM Corp., Armonk, NY).

\section{Results}

\section{Patient population}

A total of 27 patients were included, and the population consisted of 16 males and 11 females, with a mean age of $63.15 \pm 11.92$ years. According to the American Society of Anesthesiologists (ASA) classification of Physical Health, four patients (14.8\%) scored above three points (severe systemic disease that was not incapacitating), and 14 patients (51.8\%) scored above two points (mild systemic disease). The examination of initial vital signs showed that three $(11.1 \%)$ patients had high fevers above $38.0^{\circ} \mathrm{C}$, and $10(37.0 \%)$ patients had tachycardia (heart rates $>100$ beats $/ \mathrm{min}$ ). The median deltaneutrophil index (DNI) was $1.52 \pm 1.49 \%$, and the median C-reactive protein (CRP) level was $156.69 \pm$ $91.23 \mathrm{mg} / \mathrm{L}$. According to the CT images, the average dimensions of the peri-appendiceal abscesses was $5.42 \pm 1.65 \times 4.10 \pm 1.99 \mathrm{~cm}$ (Table 1$)$.

Table 1. Characteristics of the enrolled patients 


\begin{tabular}{|c|c|c|}
\hline Variable & \multicolumn{2}{|l|}{ Value } \\
\hline \multirow[t]{2}{*}{ Sex } & Male & 16 \\
\hline & Female & 11 \\
\hline \multirow[t]{2}{*}{ Age, $>65 y r s$} & \multicolumn{2}{|l|}{$13(48.1 \%)$} \\
\hline & \multicolumn{2}{|c|}{ (Mean age $63.15 \pm 11.92 \mathrm{yrs}$ ) } \\
\hline Cardiovascular disease (HTN, CAOD) & \multicolumn{2}{|l|}{$8(29.6 \%)$} \\
\hline Malignancy & \multicolumn{2}{|l|}{$8(29.6 \%)$} \\
\hline \multirow[t]{2}{*}{ ASA classification } & Above 3 points & $4(14.8 \%)$ \\
\hline & Above 2 points & $14(51.8 \%)$ \\
\hline Fever $>38.0\left({ }^{\circ} \mathrm{C}\right)$ & \multicolumn{2}{|c|}{$3(11.1 \%)$} \\
\hline Tachycardia >100 (/min) & \multicolumn{2}{|c|}{$10(37.0 \%)$} \\
\hline WBC > $10.0(\times 108 / L)$ & \multicolumn{2}{|c|}{$22(81.5 \%)$} \\
\hline Neutrophil segments > 75 (\%) & \multicolumn{2}{|c|}{$23(85.2 \%)$} \\
\hline Delta neutrophil index(DNI) (\%) & \multicolumn{2}{|c|}{$1.52 \pm 1.49$} \\
\hline C-reactive protein(CRP) (mg/L) & \multicolumn{2}{|c|}{$156.69 \pm 91.23$} \\
\hline Peri-appendiceal abscess (cm) & \multicolumn{2}{|c|}{$5.42 \pm 1.65 \times 4.10 \pm 1.99$} \\
\hline
\end{tabular}

\section{.Clinical outcomes}

A total of 27 patients were enrolled, and the mean follow-up period was 25.7 months. During the followup period, there were no deaths related to appendicitis or abscesses. Four patients died without the recurrence of appendicitis, two patients died due to underlying malignancies, and another two patients died from cerebrovascular disease and pulmonary disease. Three patients suffered from the recurrence of appendicitis requiring surgery-two open appendectomies and one right hemicolectomy. The recurrence rate was $11.1 \%$, and the mean disease-free survival was $75.7 \pm 5.6$ months (Fig.1).

\section{Discussion}

Appendicitis is the most common emergency requiring abdominal surgery. In the case of an appendiceal abscess resulting from appendiceal perforation, it is general practice to prioritize nonoperative management (NOM) methods, such as broad-spectrum antibiotics, drainage, intravenous-fluid supply, and fasting for bowel rest, rather than immediate surgical treatment. The percutaneous drainage of a 
peri-appendiceal abscess is more effective than antibiotics alone ${ }^{2}$. This treatment strategy was recognized and established as the guideline due to resulting in significantly fewer overall complications than immediate appendectomy ${ }^{9,10}$. Immediate appendectomy may be technically difficult due to inflamed tissues and the deformation of anatomical structures and locations. The operation sometimes ends up being ileocecectomy or right-sided hemicolectomy ${ }^{3,11}$. After successful nonoperative treatment, the risk of recurrent appendicitis and the incidence of complications have been shown to be low ${ }^{4,11}$. NOM has the advantage of reducing the anesthesia-related risk to patients who have many comorbidities, in that it does not involve surgery. This treatment can be a safe alternative for patients who are at high risk of needing surgical treatment. Another benefit is avoiding complications that may occur after appendectomy, such as wound infections and postoperative intestinal obstructions. Shorter hospital stays with lower hospital costs can also be beneficial ${ }^{12}$. Although NOM is an advantageous treatment method, as described in the paragraph above, there are some concerns regarding the risk of recurrence; possible appendicular or colonic neoplasms; or missing other underlying conditions, such as cancer or Crohn's disease. Therefore, the World Society of Emergency Surgery (WSES) guidelines recommend screening for appendicular or colonic neoplasms after NOM through colonoscopy or radiography ${ }^{9}$. Conventionally, interval appendectomy has been performed after NOM, but this has recently become controversial. Risk factors for performing interval appendectomy-including recurrent appendicitis, the presence of appendicolith, increased blood C-reactive protein levels, elevated percentages of white blood cells, and partial small bowel obstructions on admission-have been reported $^{13-15}$. According to the WSES guidelines, interval appendectomy is not routinely recommended and should be avoided in asymptomatic patients ${ }^{9}$. According to our data, only $11.1 \%$ of the patients who underwent NOM for peri-appendiceal abscesses received surgical treatment for the recurrence of appendicitis and abscesses. There was no disease-specific mortality, and most of the patients were treated without recurrence during the follow-up period. In our study, there were cases in which appendectomy was clearly needed, but it was not enough to offset the advantages of NOM.

The main limitations of this study are the relatively small number of cases and the retrospective design, which limits the interpretability of the results. Second, according to the guidelines, a follow-up colonoscopy is performed after discharge, but in our study, it was not necessarily performed unless there was a clear suspicion of cancer. In addition, there may have been a selection bias, as the patients chose whether to undergo NOM or surgery. Despite these limitations, our study had a long follow-up period. The fact that there was a low recurrence of appendicitis during the long follow-up period may support the NOM without appendectomy.

\section{Conclusion}

In conclusion, percutaneous drainage without appendectomy for peri-appendiceal abscesses might be a safe and effective method for selected patients with a lower risk of recurrence.

\section{Abbreviations}


NOM : nonoperative management

IRB : institutional review board

CT : computed tomogram

CRP : C-reactive protein

ASA : American Society of Anesthesiologists

DNI : delta-neutrophil index

HTN : hypertension

CAOD : coronary artery obstructive disease

WSES : the World Society of Emergency Surgery

\section{Declarations}

Ethics approval and consent to participate : This study was approved by the institutional review board (IRB No. 4-2017-1238), and the study protocol followed the Helsinki Declaration for patient protection. Informed consent was received from the enrolled patient by telephone contact.

Consent for publication : Not applicable

Availability of data and materials : The data presented in this study are available on request from the corresponding author. The data are not publicly available due to limitations outlined by our Institutional Review Board, who approved the data collection process of this study.

Competing interests : None

Funding: none

Author Contributions: C.S.P., I.A.L., and Y.T.J. wrote the manuscript. J.K.L. revised the manuscript. I.A.L. provided the images. All the authors have read and agreed to the published version of the manuscript.

\section{References}

1. Sartelli M, Abu-Zidan FM, Catena F, Griffiths EA, Saverio SD, Coimbra R, et al. Global validation of the WSES Sepsis Severity Score for patients with complicated intra-abdominal infections: a prospective multicentre study (WISS Study). World journal of emergency surgery : WJES 2015,10.

2. Sartelli M, Chichom-Mefire A, Labricciosa FM, Hardcastle T, Abu-Zidan FM, Abu-Zidan FM, et al. The management of intra-abdominal infections from a global perspective: 2017 WSES guidelines for management of intra-abdominal infections. World journal of emergency surgery : WJES 2017,12. 
3. Kim JK, Ryoo S, Oh HK, Kim JS, Shin R, Choe EK, et al. Management of appendicitis presenting with abscess or mass. J Korean Soc Coloproctol 2010,26 (6), 413-9.

4. Oliak D, Yamini D, Udani VM, Lewis RJ, Arnell T, Vargas H, et al. Initial nonoperative management for periappendiceal abscess. Dis Colon Rectum 2001,44 (7).

5. Brown CV, Abrishami M, Muller M, Velmahos GC. Appendiceal abscess: immediate operation or percutaneous drainage? Am Surg 2003,69 (10).

6. Wright GP, Mater ME, Carroll JT, Choy JS, Chung MH. Is there truly an oncologic indication for interval appendectomy? Am J Surg 2015,209 (3).

7. Kaminski A, Liu IL, Applebaum H, Lee SL, Haigh PI.,, Routine interval appendectomy is not justified after initial nonoperative treatment of acute appendicitis. Arch Surg (Chicago, III. : 1960) 2005,140 (9).

8. Al-Kurd A, Mizrahi I, Siam B, Kupietzky A, Hiller N, Beglaibter N. Outcomes of interval appendectomy in comparison with appendectomy for acute appendicitis. J Surg Res 2018,225.

9. Di Saverio S, Birindelli A, Kelly MD, Catena F, Weber DG, Sartelli M. et al. WSES Jerusalem guidelines for diagnosis and treatment of acute appendicitis. World J Emerg Surg 2016,11, 34.

10. Simillis C, Symeonides P, Shorthouse AJ, Tekkis PP. A meta-analysis comparing conservative treatment versus acute appendectomy for complicated appendicitis (abscess or phlegmon). Surg 2010,147 (6), 818-29.

11. Andersson RE, Petzold MG. Nonsurgical treatment of appendiceal abscess or phlegmon: a systematic review and meta-analysis. Ann Surg 2007,246 (5), 741-8.

12. Turhan AN, Kapan $S$, Kütükçü E, Yiğitbaş H, Hatipoğlu S, Aygün E. Comparison of operative and non operative management of acute appendicitis. Ulus Travma Acil Cerrahi Derg 2009,15 (5), 459-62.

13. Kogut KA, Blakely ML, Schropp KP, Deselle W, Hixson SD, Davidoff AM, et al. The association of elevated percent bands on admission with failure and complications of interval appendectomy. $J$ Pediatr Surg 2001,36 (1), 165-8.

14. Tsai HM, Shan YS, Lin PW, Lin XZ, Chen CY. Clinical analysis of the predictive factors for recurrent appendicitis after initial nonoperative treatment of perforated appendicitis. Am J Surg 2006,192 (3), 311-6.

15. Zerem E, Salkic N, Imamovic G, Terzić I., Comparison of therapeutic effectiveness of percutaneous drainage with antibiotics versus antibiotics alone in the treatment of periappendiceal abscess: is appendectomy always necessary after perforation of appendix? Surg Endosc 2007,21 (3), 461-6.

\section{Figures}




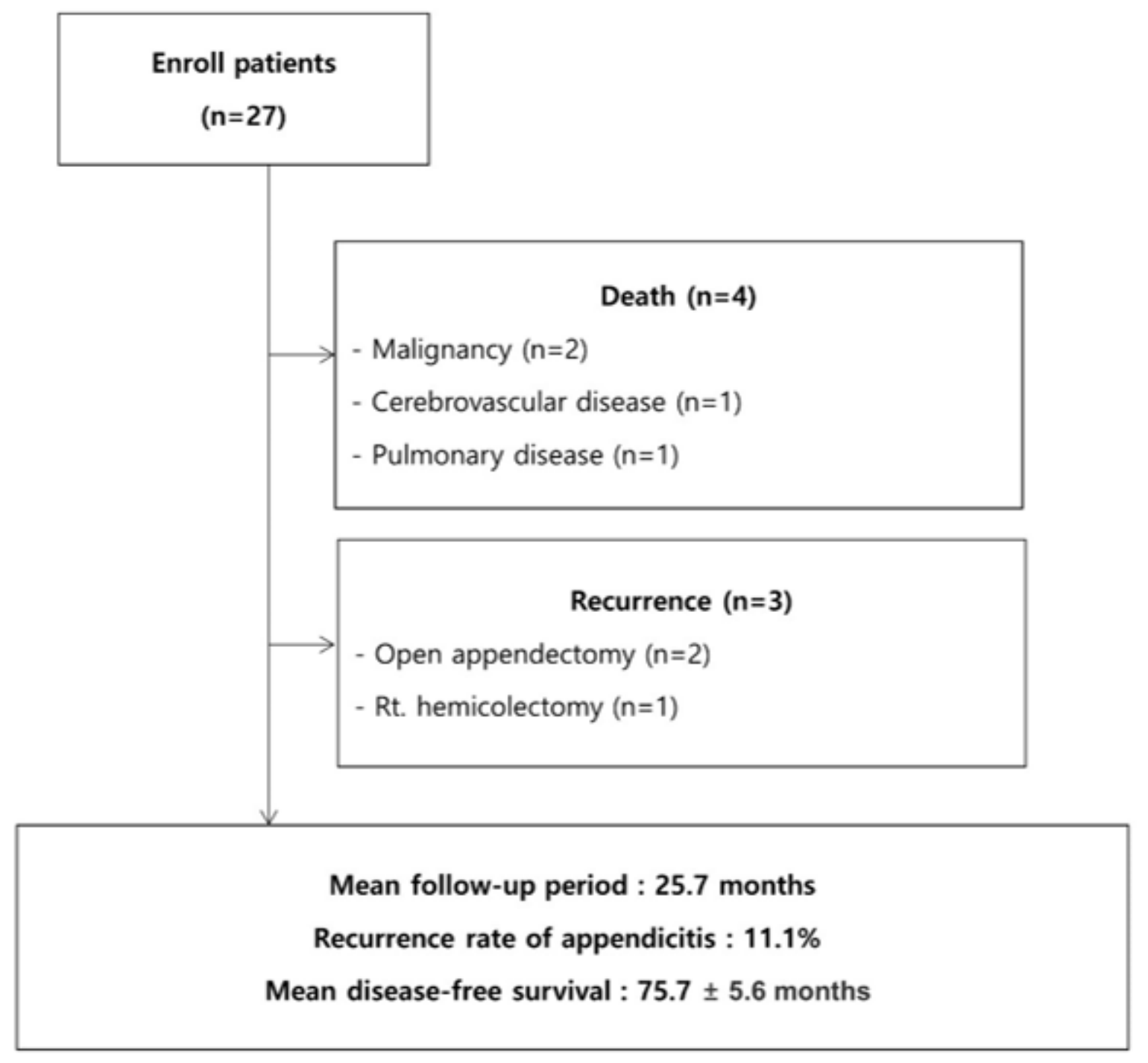

Figure 1

Flow of enrolled patients 